ISSN: 2238-8052

\title{
TERRITÓRIO, VIOLÊNCIA E MEDO: EVIDÊNCIAS NO BAIRRO DE FELIPE CAMARÃO, NATAL/RN
}

\author{
TERRITORY, VIOLENCE AND FEAR: EVIDENCE IN THE FELIPE \\ CAMARÃO, NATAL/RN NEIGHBORHOOD
}

Emilly Domingos da SILVA ${ }^{1}$

Eugênia Maria DANTAS²

Palavras-chave:

Cidade, corpos,

violência, medo.

Keywords:

City, bodies,

violence, fear

\section{R E S U M O}

Tendo como tese a ideia de que a cidade é um corpo afetado e promove afetações, estar na cidade é experimentar o encontro de corpos que estão a se mover com velocidades e ritmos diferentes. Esses encontros possibilitam a emergência de paisagens, denotando a multiplicidades das formas, contornos, sons, cores, volumes. Para o desenvolvimento dessa linha de raciocínio foi selecionado o bairro de Felipe Camarão para o estudo da paisagem, considerando o fenômeno da violência e do medo. Nessa perspectiva a percepção espacial é uma estratégia de método que diferencia a intensidade como as pessoas que habitam um local o compreendem e o decifram a partir dos laços de afeição e pertencimento. Desta forma os moradores são os agentes singulares para deliberar sobre o espaço no qual habitam, pois eles têm vivências com tais espaços rotineiramente e são partes vivas desses lugares.

\section{A B S T R A C T}

Having as thesis the idea that the city is an affected body and promotes affectations. Being in the city is experiencing the encounter of bodies that are moving with different speeds and rhythms. These encounters allow the emergence of landscapes, denoting the multiplicities of shapes, contours, sounds, colors, sizes. For the development of this line of reasoning the neighborhood of Felipe Camarão was selected for the study of the landscape, considering the phenomenon of violence and fear. In this perspective the spatial perception is a method strategy that differentiates the intensity as the people who inhabit a place understand it and decipher it from the bonds of affection and belonging. In this way residents are the sole agents to deliberate about the space in which they inhabit, since they have experiences with such spaces routinely and are living parts of these places.

\section{INTRODUÇÃO}

O estudo analisa os territórios de violência e medo do crime no bairro de Felipe Camarão, situado na Zona Oeste da cidade de Natal, capital do Rio Grande do Norte. 0 olhar geográfico para esse problema é primordial para compreender o espaço citadino e, principalmente, para identificar as relações de poder que se instauram e se estruturam nesses locais. Considerar os fatos que ocorrem no espaço é aceitar este como sendo “[...] mais do que um simples receptáculo das ações humanas, pois os

\footnotetext{
${ }^{1}$ Graduanda em Geografia da Universidade Federal do Rio Grande do Norte. E-mail: emillydoomingos@gmail.com.

2 Professora Titular do departamento da Geografia/UFRN. E-mail: eugeniadantas@yahoo.com.br.
} 
fenômenos não apenas sobre ele ocorrem, mas também são por ele produzidos" (SANTOS, 1985, p. 16).

O espaço está marcado, dentre outras coisas, pela ascendência de uma urbanização anômala e sem planejamento, corroborando para que alguns lugares apresentem processos desformes e desiguais, violentos e irrigados pela ascendência do medo do crime e da insegurança. Esse contexto afeta, em grande medida, os centros urbanos e a sociedade brasileira que busca, de modo disperso, encontrar estratégias para se proteger.

Natal, a maior cidade do Rio grande do Norte, não está imune aos efeitos do fenômeno da violência. Ficou evidente que na última década ocorreu um aumento desse problema confirmado por índices estatísticos e ratificados em relatos, que colocam a sensação de insegurança como um grave problema enfrentado no cotidiano. A tríade medo do crime, insegurança e violência induzem a população a buscar meios para se proteger, seja pela busca de aparatos tecnológicos (câmeras, cercas, vigias), seja pela mudança de hábitos. A exemplo disso podemos identificar o recuo das pessoas em sentar à calçada para conversar com os vizinhos. A expansão da violência tornou esse mecanismo de convivialidade e vizinhança um ato de exposição que coloca em risco a própria vida.

A tessitura territorial de Natal apresenta bairros onde ocorrem uma maior concentração de crimes de violência letal. As Zonas Administrativas Norte e Oeste têm sido identificados com um número significativo de ocorrências, sendo o bairro de Felipe Camarão localizado na zona Administrativa Oeste um exemplo. Assim, compreender em que medida Felipe Camarão se constitui como território de violência e medo, considerando os índices de violência letal intencional, é o objetivo desse trabalho.

Vale salientar que a escolha do bairro de Felipe Camarão como objeto de estudo deveu-se a existência de laços afetivos que tenho com o lugar. Desde criança vivo em constante trânsito entre os bairros de Cidade Nova1 e Felipe Camarão, pois minha mãe era moradora deste.

Felipe Camarão carrega o estigma de degradante e de perigoso. Para testar esse estigma, fiz uma exploração pelo bairro com colegas do curso de Geografia da Universidade Federal do Rio Grande do Norte (UFRN), Campus de Natal, usando o Google Street View. Com esse dispositivo os estudantes passavam pelas ruas e só conseguiam enxergar esgoto a céu aberto, a falta de pavimentação e drenagem, a carência de estrutura básica que acentua, na paisagem, os problemas como o enredo para as vivências.

Esse campo de visibilidade que se forma para o olhar estrangeiro acomoda-se de outra maneira para aquele que descreve a paisagem como um visível vivido. Desse modo, eu, tendo que está entre os bairros Cidade Nova e Felipe Camarão, percebo o que os colegas identificaram mais ultrapasso a paisagem como estigma, para encontrar, também, na mesma rua o seu Chico vendedor de batata doce da minha infância, o lugar onde aprendi a andar de bicicleta, a passagem para chegar a minha avó. 
Sendo assim fui remetida a uma visão mais complexa do bairro. Sem abandonar os laços afetivos os elasteci para ver os problemas que afetam o cotidiano do morador do bairro e a dificuldade de enxergar os problemas estruturais existentes quando são reduzidos a condições estigmatizadas. Percebi, com isso, o lado do cotidiano em sua matriz mais perversa que é a de embotar a realidade, induzir e reduzir a experiência a práticas espaciais a padrões discursivos normalizadores.

Para seguir nos estudos efetuamos um levantamento bibliográfico que resultou na sistematização de ideias referentes a autores como BAUMAN (2008), TUAN (2005), BAYER (2016), MELGAÇO (2010), ARENDT (1987), HAESBAERT (2004). Foi efetuadas pesquisas em fontes como, o Observatório da Violência do Rio Grande do Norte (OBVIO), em matérias jornalísticas que ressaltam os Crimes de violência letal intencional (CVLI) no perímetro do bairro Felipe Camarão. Foram feitas diversas explorações em campo, o que subsidiou o entendimento para o mapeamento do contorno do bairro, e uma divisão simbólica em zonas que levam em conta as considerações feitas pelos moradores. Nessas explorações geográficas as conversas com os moradores foram importantes para entendermos mais sobre o local e a problemática deste trabalho.

Deste modo, o trabalho está subdividido em três seções. No primeiro momento discutimos o espaço citadino e suas novas ramificações, especificamente no bairro de Felipe Camarão, Natal-RN. No segundo momento analisamos o conceito de território e suas novas ramificações com o fenômeno da violência. E por fim refletimos sobre os índices de CVLI em Felipe Camarão e sua relação com a territorialização da violência e seus agentes.

\section{CIDADE: A ASPIRAÇÃO PERFEITA E HARMÔNICA DA HUMANIDADE (?)}

O medo está ligado ao ser humano a partir dos seus diferentes vínculos. A acentuação desse sentimento decorre das variações e posicionamentos dos sujeitos no espaço, de modo que podemos ter medo do escuro, de adoecer, de morrer, de ficar sozinho, de estar na multidão, de frequentar determinados lugares da cidade, de ser assaltado. 0 medo tem componentes individuais e sociais, culturais e psíquicos, ambientais e simbólicos. Bauman (2008) afirma que esse sentimento está ligado a nossas incertezas e as nossas ignorâncias sobre o mundo, a vida, o físico e o metafísico.

Desta maneira o medo é um sentimento comum para todos os homens, que são decorrentes da sensação de insegurança e vulnerabilidade relacionada ao perigo. 0 medo é um fenômeno que é refletido no espaço das existências materiais e imateriais, que contornam o vivo e o não vivem. Ao ser tratado com tal ele se materializa por meio de um sistema de ações e objetos que se evidencia no espaço, fomentando práticas espaciais territorializadas. 0 medo advém de inúmeros fatores, mas nenhum deles é tão expressivo quanto o medo do crime. Esse fenômeno contemporâneo toma uma grande parcela de atenção e esforço, diário, da população que tenta, em geral, prevenir-se e se proteger. 
O medo e a violência urbana vêm afetando as cidades cujos efeitos são sentidos cada vez mais pelo isolamento e individualismo do ser humano dos espaços públicos e de convívio coletivo e de vizinhança. Segundo Tuan a "cidade representa a maior aspiração da humanidade em relação à ordem perfeita e harmônica, tanto em sua estrutura arquitetônica como nos laços sociais", mas no decorrer do tempo "a cidade tem sido oprimida pela violência e pela ameaça constante do caos" (2005, p. 231251).

No tocante a identificação das cidades com índices consideráveis de periculosidade a organização mexicana Seguridad Justicia y $\mathrm{Paz}^{3}$, efetuou um estudo onde foi identificado as 50 cidades mais perigosas do mundo. A instituição utilizou para sua pesquisa os dados de homicídios fornecidos pelos poderes Estatais no ano de 2018.

A ONG mexicana utiliza como critérios para seleção das cidades os seguintes pré-requisitos:

1) Deve ser uma unidade urbana claramente definida. Não pode ser uma área ou jurisdição que faz parte de uma cidade ou pertence a um município (ou jurisdição equivalente) que seja predominantemente rural;

2) A cidade em questão deve ter 300 mil ou mais habitantes, segundo Informações Estatais;

3) Os dados devem corresponder a homicídios ou homicídios dolosos, mortes intencionais ou por agressão;

4) Os números de homicídio devem vir de fontes oficiais ou fontes alternativas. Em alguns casos, os dados são o resultado de uma contagem própria, a partir da análise de anotações jornalística;

5) Os números devem corresponder ao ano anterior.

Segundo a Organização Seguridad Justicia y Paz (2018) o cálculo para obtenção da taxa consiste em dividir o número de homicídios entre o número total de habitantes e o resultado é multiplicado por 100 mil. Vale ressaltar que alguns governos buscam manipular os dados para obter índices menores do que a realidade apresenta. Sendo assim, a organização busca fontes de informações alternativas, ou seja, filtrar dados através de matérias jornalísticas para constatar a veracidade dos dados. No caso dos dados fornecidos estarem incompletos são realizadas projeções estatísticas. Considerando esse modelo, as 50 cidades mais violentas do mundo foram ranqueadas e Natal aparece em quarto lugar, no ano de 2018 (Tabela 01).

\footnotetext{
${ }^{3}$ A organização mexicana Seguridad Justicia y paz é um conselho Cidadão de Segurança Pública e Justiça Criminal do México, que divulga os rankings mundiais da violência desde 2013. A organização da sociedade civil, fundada em 2002, tem como objetivo alcançar a plena vigência dos direitos humanos, em particular os direitos à segurança pública e à justiça criminal. A ONG la Seguridad Pública y la Justicia Penal A.C. é uma rede apartidária, secular e independente. Que Desde a sua fundação, emitiu mais de 600 documentos através de conferências de imprensa, palestras, ensaios, artigos e livros.
} 
Tabela 01. As 50 cidades mais violentas do mundo 2018.

\begin{tabular}{|c|c|c|c|c|c|}
\hline Posição & Cidade & País & Homicídios & Habitantes & $\begin{array}{c}\text { Taxa (por } 100 \\
\text { mil habitantes) }\end{array}$ \\
\hline 10 & Los Cabos & México & 365 & 328.245 & 111,33 \\
\hline $2^{o}$ & Caracas & Venezuela & 3.387 & 3.046 .104 & 111,19 \\
\hline $3^{\circ}$ & Acapulco & México & 910 & 853.646 & 106,63 \\
\hline 40 & Natal & Brasil & 1.378 & 1.343 .573 & 102,56 \\
\hline $5^{\underline{o}}$ & Tijuana & México & 1.897 & 1.882 .492 & 100,77 \\
\hline $6^{0}$ & La Paz & México & 259 & 305.455 & 84,79 \\
\hline $7 \underline{0}$ & Fortaleza & Brasil & 3.270 & 3.917 .279 & 83,48 \\
\hline $8^{\circ}$ & Victoria & México & 301 & 361.078 & 83,32 \\
\hline 9o & Guayana & Venezuela & 728 & 906.879 & 80,28 \\
\hline $10^{\circ}$ - & Belém & Brasil & 1.743 & 2.441 .761 & 71,38 \\
\hline $11^{\mathrm{o}}$ & Vitória da Conquista & Brasil & 245 & 348.718 & 70,26 \\
\hline $12^{\circ}$ & Culiacán & México & 671 & 957.613 & 70,1 \\
\hline $13^{\circ}$ & St. Louis & Estados Unidos & 205 & 311.404 & 65,83 \\
\hline $14^{\circ} \mathrm{o}$ & Maceió & Brasil & 658 & 1.029 & 63,94 \\
\hline $15^{\circ}$ & Cape Town & África do Sul & 2.493 & 4.004 .793 & 62,25 \\
\hline $16^{\circ}$ & Kingston & Jamaica & 705 & 1.180 .771 & 59,71 \\
\hline $17^{\circ}$ & San Salvador & El Salvador & 1.057 & 1.789 .588 & 59,06 \\
\hline $18^{\circ}$ & Aracaju & Brasil & 560 & 951.073 & 58,88 \\
\hline 190 & Feira de Santana & Brasil & 369 & 627.477 & 58,81 \\
\hline $20^{\circ}$ & Juárez & México & 814 & 1.448 .859 & 56,16 \\
\hline $21^{\mathrm{o}}$ & Baltimore & Estados Unidos & 341 & 614.664 & 55,48 \\
\hline $22^{\circ}$ & Recife & Brasil & 2.180 & 3.965 .699 & 54,96 \\
\hline $23^{\circ}$ & Maturín & Venezuela & 327 & 600.722 & 54,43 \\
\hline $24^{\circ}$ & Guatemala & Guatemala & 1.705 & 3.187 .293 & 53,49 \\
\hline $25^{\circ}$ & Salvador & Brasil & 2.071 & 4.015 .205 & 51,58 \\
\hline $26^{\circ}$ & San Pedro de Sula & Honduras & 392 & 765.864 & 51,18 \\
\hline $27^{\circ}$ & Valencia & Venezuela & 784 & 1.576 .071 & 49,74 \\
\hline $28^{\circ}$ & Cali & Colômbia & 1.261 & 2.542 .876 & 49,59 \\
\hline 290 & Chihuahua & México & 460 & 929.884 & 49,48 \\
\hline $30^{\circ}$ & João Pessoa & Brasil & 554 & 1.126 .613 & 49,17 \\
\hline $31^{\circ}$ & Obregón & México & 166 & 339.000 & 48,96 \\
\hline $32^{\circ}$ & San Juan & Porto Rico & 169 & 347.052 & 48,7 \\
\hline $33^{\circ}$ & Barquisimeto & Venezuela & 644 & 1.335 .348 & 48,23 \\
\hline $34^{\circ} \mathrm{O}$ & Manaus & Brasil & 1.024 & 2.130 .264 & 48,07 \\
\hline $35^{\circ}$ & Distrito Central & Honduras & 588 & 1.224 .897 & 48 \\
\hline $36^{\circ}$ & Tepic & México & 237 & 503.330 & 47,09 \\
\hline $37^{\circ}$ & Palmira & Colômbia & 144 & 308.669 & 46,65 \\
\hline $38^{\circ}$ & Reynosa & México & 294 & 701.525 & 41,95 \\
\hline 390 & Porto Alegre & Brasil & 1.748 & 4.268 .083 & 40,96 \\
\hline $40^{\circ}$ & Macapá & Brasil & 191 & 474.706 & 40,24 \\
\hline $41^{\circ}$ & Nova Orleans & Estados Unidos & 157 & 391.495 & 40,1 \\
\hline $42^{\circ}$ & Detroit & Estados Unidos & 267 & 672.795 & 36,69 \\
\hline $43^{\circ}$ & Mazatlán & México & 192 & 488.281 & 39,32 \\
\hline $44^{\mathrm{o}}$ & Durban & África do Sul & 1.396 & 3.661 .911 & 38,12 \\
\hline $45^{\circ}$ & Campos de Goytacazes & Brasil & 184 & 490.288 & 37,53 \\
\hline $46^{\circ}$ & Nelson Mandela Bay & África do Sul & 474 & 1.263 .051 & 37,53 \\
\hline $47^{\circ}$ & Campina Grande & Brasil & 153 & 410.332 & 37,29 \\
\hline $48^{\circ}$ & Teresina & Brasil & 315 & 850.198 & 37,05 \\
\hline 490 & Vitória & Brasil & 707 & 1.960 .213 & 36,07 \\
\hline $50^{\circ}$ & Cúcuta & Colômbia & 290 & 833.743 & 34,78 \\
\hline
\end{tabular}

Fonte: Seguridad justicia y paz (2018) 
Ao analisar a tabela é possível constatar que o Brasil é o país com mais cidades posicionadas nesse ranking, totalizando 17. A cidade de Los Cabos/México lidera a lista como a mais violenta do mundo, apresentando taxa de 111,33 homicídios por 100 mil habitantes. Sendo seguida pela capital da Venezuela, Caracas 4 .

Natal (RN) evidencia uma taxa de 102,56 homicídios por 100 mil habitantes, sendo a quarta cidade mais perigosa do mundo. No contexto das cidades nordestinas são citadas ainda Fortaleza (CE), Vitória da Conquista (BA), Maceió (AL), Aracaju (SE), Feira de Santana (BA), Recife (PE), Salvador (BA), João Pessoa (PB), Campina Grande (PB) e Teresina (PI).

Nos últimos anos é possível observar o crescimento nos índices de violência no Estado do Rio Grande do Norte (RN) (Tabela 02). Em menos de uma década, o RN deixou de ser um estado pacato, onde os municípios contavam com taxas de violência baixas, transfigurando-se em um lugar com altos índices de criminalidade e violência. Chama a atenção o aumento das taxas de condutas violentas letais intencionais (CVLI) no Estado do Rio Grande do Norte.

Tabela 02. Os 20 municípios mais violentos do Rio Grande do Norte.

\begin{tabular}{c|c|c|c|c}
\hline \multirow{2}{*}{ MUNICÍPIOS } & \multicolumn{4}{|c}{ Condutas violentas letais intencionais de Jan 31 de Mai } \\
\cline { 2 - 5 } & 2015 & 2016 & 2017 & 2018 \\
\hline Natal & 205 & 243 & 269 & 197 \\
Mossoró & 62 & 111 & 111 & 106 \\
Parnamirim & 62 & 77 & 71 & 44 \\
são gonçalo & 28 & 51 & 36 & 49 \\
Ceará-mirim & 23 & 42 & 67 & 24 \\
Macaíba & 30 & 26 & 40 & 38 \\
Extremoz & 10 & 14 & 23 & 26 \\
Nísia Floresta & 9 & 15 & 32 & 14 \\
São José do Mipibu & 12 & 17 & 19 & 12 \\
Assú & 10 & 10 & 11 & 22 \\
Caicó & 10 & 17 & 19 & 6 \\
João camâra & 5 & 6 & 20 & 15 \\
Barauna & 12 & 8 & 16 & 8 \\
Canguaretama & 4 & 5 & 9 & 14 \\
Touros & 2 & 4 & 18 & 6 \\
Santa Cruz & 12 & 8 & 7 & 2 \\
São Paulo do Potengi & 4 & 9 & 8 & 8 \\
Currais Novos & 12 & 2 & 8 & 2 \\
Macau & 8 & 6 & 9 & 2 \\
Areia Branca & 1 & 6 & 8 & 11 \\
Outros & 153 & 120 & 230 & 235 \\
\hline
\end{tabular}

Fonte: Observatório da Violência (2018)

\footnotetext{
${ }^{4}$ Vale salientar que a Venezuela ocupa a segunda posição no ranking das cidades mais perigosas, porém a mesma vem passa por uma crise econômica e política a mais de quatro anos. A insatisfação do povo venezuelano tem gerado uma onda de protestos que acabam em conflitos violentos, tal fato corrobora para o aumento da violência letal intencional na cidade de Caracas a capital da Venezuela.
} 
De acordo com o que foi apresentado, Natal lidera o ranking de municípios mais violentos, no período de 2015 apresentava 205 crimes de violência letal intencional, enquanto em 2016 foram registrados 243 assassinatos, o que representou um aumento de 18,5\%. Se levado em conta o ano de 2017 o quadro é ainda mais assustador, pois ocorreram 269 homicídios o que representa um aumento de 22\%. Segundo o OBVIO, o Rio Grande do Norte apresentava a terceira menor taxa de homicídio do Brasil em 2006, mas em menos de uma década ocorreu à elevação desse tipo de crime, um aumento de 256,9\% na taxa de homicídio a cada 100 mil habitantes.

Ainda considerando os dados da tabela 02 , no RN a faixa etária mais atingida pelos CVLI são os jovens entre 15 e 29 anos. Nesse sentido são 125,6 homicídios a cada 100 mil habitantes. Em 2016, $60,8 \%$ das mortes violentas eram dos jovens dessa faixa etária. Se levarmos em consideração as mortes totais de 1.854 óbitos de 2016 no Estado 1129 tinha entre 15 e 29 anos.

Nos últimos anos Natal passou a integrar o quarto lugar no ranking das cidades mais violentas do mundo, esse evento tem se espraia de forma desigual no território da cidade. Segundo o OBVIO, as Zonas Administrativas Norte e Oeste evidenciam as maiores taxas de CVLI. Essas áreas estigmatizadas, tidas como as mais violentas e mais precárias devido a inúmeros fatores entre eles os baixos índices de qualidade de vida, renda, educação, emprego, esgotamento sanitário e outros itens básicos.

Nessas Zonas as políticas públicas e o Estado são ineficientes, deixando um vazio para a atuação de outros agentes, que se estabelecem produzindo novas relações de domínio e controle desse território. Nessas zonas quem são esses agentes? A resposta a tal pergunta é imprecisa, pois é extremamente difícil fazer um mapa com essa informação. A falta de registros e a dispersão de dados, as lacunas e imprecisões existentes tornam o caminho mais incerto. No entanto nos últimos três anos alguns eventos que ocorreram na cidade (Rebelião em presídios, queima de ônibus, assaltos a caixas de bancos) vêm evidenciando com mais precisão a existência do crime organizado.

É no território que ocorre a junção de elementos como medo do crime, insegurança e violência, que se articulam, completa-se e se contradiz, sendo necessário compreender que a violência como fenômeno que se territorializa.

\section{TERRITÓRIO DO MEDO E DA VIOLÊNCIA: ALGUMAS EVIDENCIAIS TEÓRICAS}

É de fundamental importância compreender o território para compreender a dinâmica da violência, por isso, trazemos como exemplo o bairro de Felipe Camarão (Mapa 01) como referência geográfica da relação construída na tríade território, violência e medo do crime. A partir dos vazios de poder deixados pelo estado e da apropriação pela territorialização do crime, a trama locacional que envolve o bairro vem acentuando nos moradores residentes desse aglomerado a sensação de insegurança e medo do crime, visto as sucessivas ondas de violência as quais estão expostos diariamente nesse lugar. Num jogo de ambiguidades que envolve violência e poder, o espaço vai sendo 
um campo para a territorialização do crime, de modo que a população vai perdendo de vista a necessidade de diferenciar violência e poder.

De acordo com Arendt (1994, p.42) o poder não advém da violência, pois a violência “[...] sempre pode destruir o poder; do cano de uma arma emerge o comando mais efetivo, resultando na mais perfeita e instantânea obediência. 0 que nunca emergirá daí é o poder". Os ensinamentos dessa filósofa são importantes para pensarmos o território como campo de forças disputados pelo crime, pelo estado que quer combatê-lo, pela população que quer se proteger. Onde está o poder, nesse jogo de múltiplas forças e interesses?

0 território segundo Haesbaert (2004) “(...) vincula-se a categoria poder, porém não apenas ao poder no sentido concreto de dominação (poder político), mas também ao poder simbólico, ligado à apropriação de determinados grupos para com o espaço vivenciado" (Haesbaert, 2004, p. 95). A partir dessa perspectiva o território é uma relação de dominação e apropriação socioespaciais, "desdobrando-se ao longo de um continuum que vai da dominação político-econômica mais 'concreta' e 'funcional' à apropriação mais subjetiva e/ou 'cultural-simbólica (Haesbaert, 2004, p.96)”.

Desta forma o território é constituído pelas relações sociais que se dão a partir do espaço geográfico. A busca pela compreensão e definição da semiologia territorial é muito complexa e deve ser levado em consideração as relações de totalidade, multiescalar e multidimensional. Segundo Raffestin (1993) o território se forma a partir do espaço, é o resultado de uma ação conduzida por um ator sintagmático. 0 território é a matéria-prima um agente condicionante e condicionado por relações de poder que se instauram em determinado local. Para Raffestin (1993, p. 150) "toda prática espacial (...) induzida por um sistema de ações ou de comportamentos se traduz por uma 'produção territorial' que faz intervir tessitura, nó e rede". Sendo assim, o território traz a construção material e a dimensão simbólica do vivido. Sendo esses, concomitantemente, produto e produtor de ambiguidades no espaço.

Há uma tênue relação entre o território e o poder partindo da ideia que o Poder com "P" maiúsculo diz respeito ao Estado; e o poder com "p" minúsculo é mais amplo e está relacionado a cada relação social. Deve-se destacar que o poder é multidimensional, ou seja, advém de todo tipo de relação. Uma das características mais marcantes, nessa perspectiva, é que ele não é apenas vertical, mas ganha uma dimensão horizontal. Esta concepção torna-se importante para compreender as relações de poder no território, na medida em que se acrescenta a possibilidade de enxergar o campo de força não a partir de um centro, mas disseminado pôr em diferentes pontos que podem emergir de qualquer lugar. 0 território é, portanto, abrigo e disseminador das forças que atuam no jogo de dominação e subordinação especializadas na territorialização do crime. Destacamos, portanto, a violência como um dos agentes dessa territorialização.

Para a Organização Mundial de Saúde (OMS) violência é definida como:

Uso intencional da força física ou do poder real ou em ameaça, contra si próprio, contra outra pessoa, ou contra um grupo ou uma comunidade, que resulte ou tenha 
qualquer possibilidade de resultar em lesão, morte, dano psicológico, deficiência de desenvolvimento ou privação (KRUG et al., 2002, P. 5).

A violência é um fenômeno de extrema complexidade advindo de inúmeras causas, que submete os indivíduos as suas múltiplas variações. A violência é inerente ao homem, pois:

Não se conhece nenhuma sociedade totalmente isenta de violência. Ela consiste no uso da força, do poder e de privilégios para dominar, submeter e provocar danos a outros: indivíduos, grupos e coletividades. Há sociedades mais violentas do que outras, o que evidencia o peso da cultura na forma de solução de conflitos (MINAYO, 2005, p.23).

Tenório e Pimentel (2002) afirmam que cada cultura e sociedade é quem vai indicar os significados e sentidos de violência, cada sociedade constrói aquilo que é tolerável. Nessa direção, o corpo é o meio primeiro registro pelo qual o homem e o mundo se conectam e ao mesmo tempo constrói os mecanismos de interdição, tolerância e violência.

Segundo FOUCAULT (2004, p. 126) “[...] em qualquer sociedade, o corpo está preso no interior de poderes muito apertados, que lhe impõem limitações, proibições ou obrigações". Sendo assim, o corpo registra e cria as transições que perpassam todo o corpo social; gera transformações e modificações nas condutas dos seres humanos e da sociedade. 0 corpo é um agrupamento de forças que se encontram em continuum confronto. Não estando limitado a concepções orgânicas, física ou material, ele também se desmaterializa, quando exposto ao perigo, real ou hipotético, da insegurança, do medo e da violência.

A partir das afetações sofridas pelo corpo, ocorre assim a necessidade de se resguardar através da consolidação de novos mecanismos de proteção ao qual o indivíduo julga ser necessário para combater ou inibir as práticas espaciais da violência, buscando impedir que a violência chegue até esse corpo. 0 campo de força exercido pela violência pode ser observado através da materialidade é da técnica que territorializa corpos por toda cidade. Faz-se necessário compreender que a violência como um fenômeno que territorializa através de uma tríade de processos. Segundo BAYER (2016) essa função ocorre a partir da: a) afetação do corpo; b) consolidação na materialidade, através de práticas espaciais; c) rotulação do espaço.

Ainda de acordo com BAYER (2016) a rotulação de espaços vai ocorrer de acordo com a classificação dos corpos e das materialidades existentes nesse local onde ele será rotulado como violento, inseguro, perigoso etc. 0 mesmo ocorre com determinadas áreas da cidade que são taxadas de acordo com os grupos socias existentes, que são tidos como "infratores em potencial", esse grupo sociais abrange todos os "indesejáveis" sendo eles flanelinhas, carroceiros, pedintes etc. Nessas áreas, ocorrerá a taxação de lugares que são caracterizados por seus atributos, seja pela precariedade na iluminação, ou ruas esquisitas, praças e casas abandonadas, tais locais são tidos como ambientes propícios ao crime. 
Portanto, o território é uma composição de funcionalidade e simbolismo, pois é atrelado as funções e significados que vão de proteção a abrigo, passando a ser provedor de recursos naturais e matérias-primas que variam de acordo com as demandas sociais existentes.

\section{TERRITÓRIO DO MEDO E DA VIOLÊNCIA: FELIPE CAMARÃO E ALGUMAS EVIDÊNCIAS EMPÍRICAS}

Nesse cenário de violência que se espraia pela cidade de Natal, destaca-se o bairro de Felipe Camarão, que está situado na Zona Oeste da cidade (Figura 01).

Figura 01. Bairro de Felipe Camarão

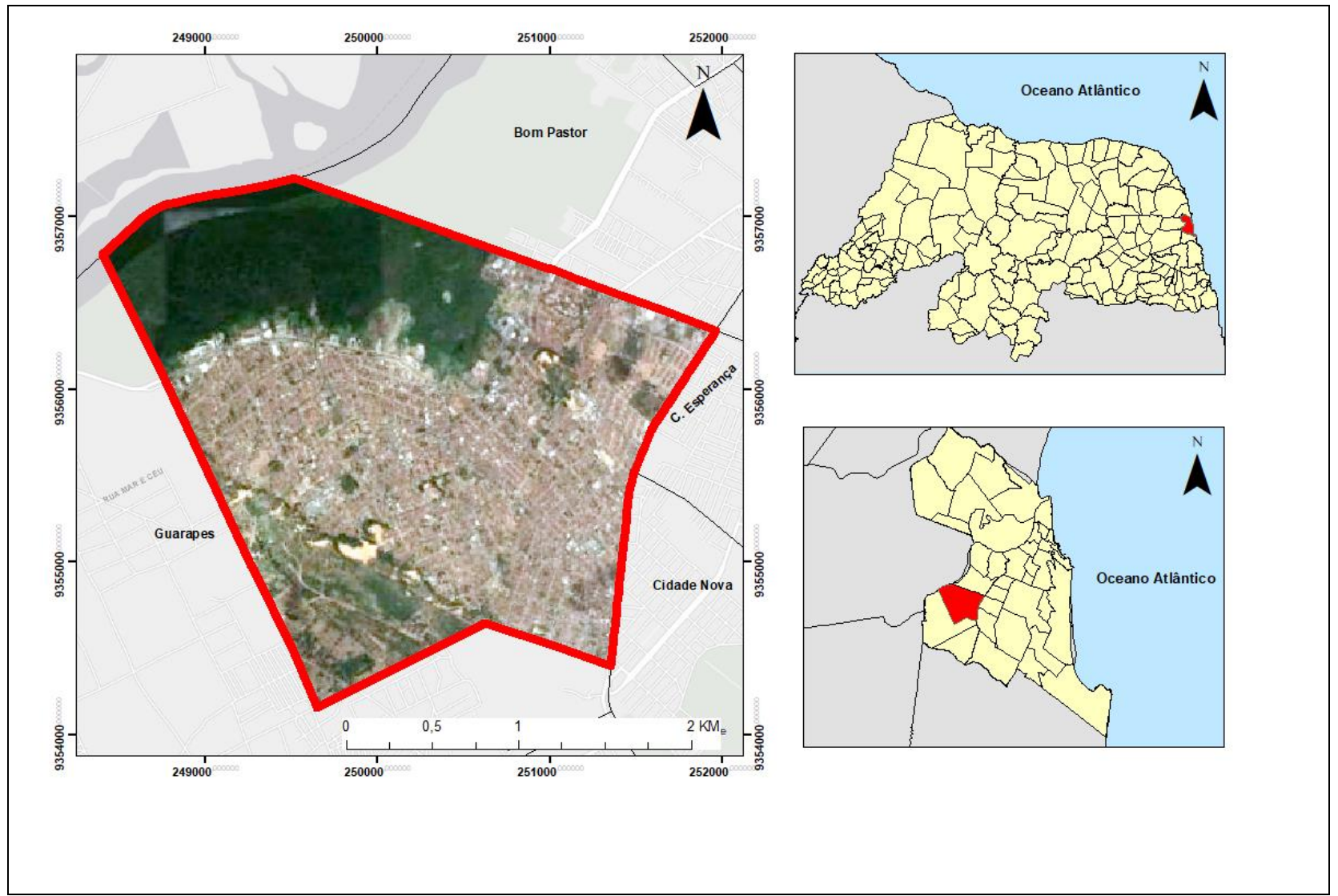

Fonte: IBGE (2012); Google Earth (2016)

Segundo o documento Natal: meu bairro, minha cidade - 2009 elaborado pela Secretaria de Meio ambiente e urbanismo (SEMURB), a ocupação do bairro de Felipe Camarão iniciou-se no final da década de 1970. A proprietária das terras era a Viúva Machado (Personagem da região que tinha a reputação de ingerir o fígado de crianças da região). A esposa do comerciante Manoel Machado, um comerciante Português o mais rico de Natal na época, vendeu parte dessas terras em 1962. Um dos 
compradores era o alemão Gerold Gepper, que através do intermédio da empresa GERNA, criou um loteamento denominado Reforma.

No início do seu processo habitacional o bairro era denominado Peixe Boi, pois segundo relatos de moradores que residiam no local, nas margens do Mangue do Rio Potengi havia a presença desses enormes mamíferos, fazendo com que o local fosse conhecido e chamado assim. Com o passar do tempo o bairro mudou de nome, tornando-se Felipe Camarão, em homenagem ao chefe indígena que lutou como aliado dos Portugueses contra os Holandeses aqui em Natal. A lei de criação do bairro é a 4.330/93, segundo a SEMURB Felipe Camarão conta com uma área de 663,4 hectares, apresentando 50.997 habitantes (IBGE 2010), que apresentam um rendimento mensal de R\$:327,28.

A localidade apresenta altos índices de desigualdade socioespaciais, que corroboram para a formação de territórios do medo e violência, pois em tal ambiente a miséria se encontra espacializada contribui como modeladora desses territórios.

Figura 2. Divisão simbólica do Bairro de Felipe Camarão

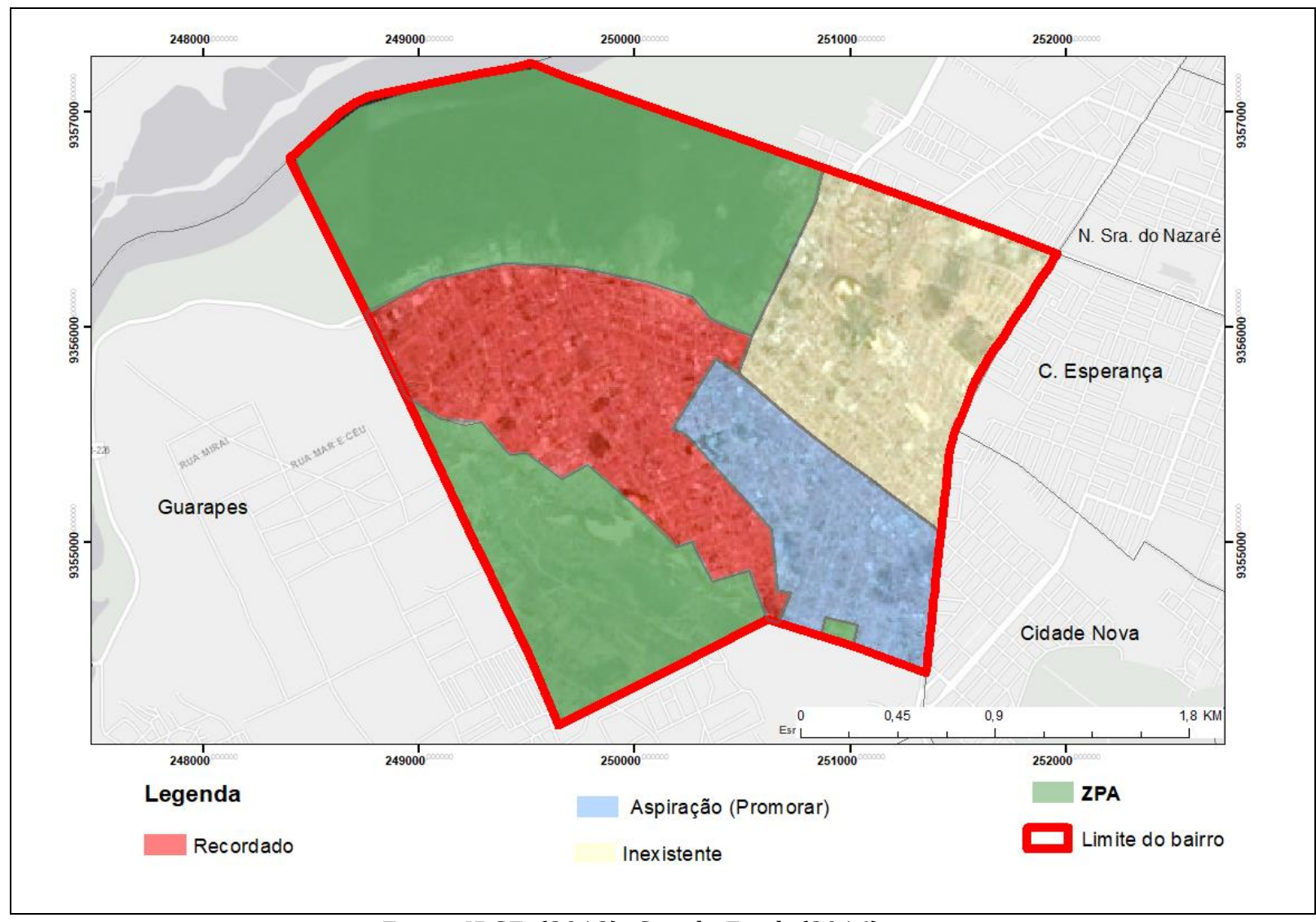

Fonte: IBGE (2012); Google Earth (2016)

Felipe Camarão é o segundo bairro mais violento da cidade de Natal, esse quadro de violência exacerbada é sentido pela população, que revelou por meio de suas impressões e vivências, o pensar sobre o problema. Nas explorações geográficas que fizemos pudemos conversar com 34 pessoas que 
corroboraram para a criação do mapa com dimensões simbólicas de Felipe Camarão (Mapa 02). Esse mapa encontra-se subdividido em Felipe Camarão Recordada, a Aspiração (Promorar) e a inexistente.

O Felipe Camarão Recordada é onde há concentração de crimes de violência letal intencional, dessa forma esse recorte espacial diz respeitos àquilo que as pessoas acreditam que seja o bairro. $\mathrm{Ou}$ seja, essa divisão diz respeito ao imaginário popular a respeito do bairro de Felipe Camarão representando toda o discurso de violência e medo do crime que está disseminado e corroborando para manutenção da imagem estigmatizada do bairro.

Quanto a Aspiração refere-se à parcela do bairro que é o "modelo a seguir", nessa zona há baixos índices de homicídios, onde é possível observar pessoas sentas em suas calçadas conversando com a vizinhança, enquanto observam as crianças a brincar na rua. Essa parcela do bairro foi apontada pelos moradores como sendo a mais segura. Já a Felipe Camarão Inexistente corresponde à parcela do bairro que foi esquecida pelo poder público e pelos próprios moradores, essa zona mostrou-se como a mais carente, apresentando altos índices de favelização que são resultantes no processo de segregação e exclusão social dos indivíduos que vivem nessa área.

Em tais explorações podem-se questionar os moradores se já haviam presenciado algum tipo de violência, os 34 responderam que sim, e citaram crimes como assaltos, homicídios, troca de tiros, linchamento, esfaqueamento. Quando o quesito é sensação de segurança 97,06\% dos interlocutores afirmaram que não se sentiam seguros ao andar pelas ruas de Felipe Camarão. Ou seja, os moradores do bairro têm receio de se deslocar, um direito básico previsto pela constituição. Além das dificuldades enfrentadas diariamente pelos moradores, seja pela falta mobilidade urbana, insegurança e infraestruturas, esses moradores ainda lidam com o preconceito por serem de uma área periférica.

\footnotetext{
Já fui acusada de ser uma ameaça por morar em Felipe Camarão; As pessoas acham que aqui só moram bandidos, drogados...; Medo, as pessoas acharam que eu tinha uma má índole; Sou moradora de um dos piores bairros da capital; Quando menor, me chamaram de pretinha favelada, cabelo de Bombril, essas coisas; (Moradores, 2019)
}

Essas afirmações encontram-se as marcas de uma trama locacional citadina tecida por qualificações que estigmatizam e segrega os moradores a espaço fechados em ilhas de preconceitos que inibem o direito a cidade.

\section{CONCLUSÃo}

A análise acerca de uma temática tão delicada com a violência urbana se dispõe como um elemento fundamental, pois a partir do estudo de aglomerados subnormais como Felipe Camarão, ajuda-nos a compreender sobre as dinâmicas espaciais desses locais. 0 que é de extrema importância 
devido às atuais ramificações sociais que geram desigualdades, ampliando as mazelas sociais, que atingem a população.

A violência é o medo são componentes espaciais, e os sujeitos vivem e se organizam de acordo com o que deduzem ser a razão da insegurança. Tais movimentos ajudam na construção de territórios regidos pelo medo do crime, que vão fomentar novas barreiras a partir da categorização do inseguro.

0 medo derivado passou a controlar a vida dos cidadãos, que se enclausuram em busca de segurança, seja por meio da tecnoesfera, onde se é investido cada vez mais em aparatos tecnológicos como câmeras, cercas, alarmes etc. Ou através da psicoesfera, que deixa as pessoas em estado de constante alerta. Viver nas grandes cidades passou a ser uma forma de resistência. "Em nenhum outro lugar a vida está sendo um jogo tão perigoso como nas grandes cidades (MORAIS, 1981, p.11)

Vale salientar que mesmo tratando do bairro de Felipe Camarão, tal processo não se restringe a esse local, tendo em vista que outros bairros da capital apresentam processos semelhantes. Desta forma a análise territorial com enfoque no fenômeno de territorialização da violência e do medo crime ajudam como reflexão para outras localidades.

Debater sobre tal temática é de extrema importância, pois existem inúmeros questões que precisam ser respondidas. Assim a ciência geográfica funciona como um instrumento importante que ajuda na compreensão da realidade. Sendo um elemento primordial para o planejamento urbano e das instituições estatais responsáveis pela elaboração de políticas públicas.

\section{REFERÊNCIAS}

ARENDT, Hannah. A Condição Humana. Rio de Janeiro: Forense Universitária, 1987.

BAIERL, Luzia Fátima. Medo social: da violência visível ao invisível da violência. [S.l.]: Cortez, 2004. 204 p.

BAUMAN, Zygmunt. Medo Liquido. [S.l.]: LZAHAR, 2008. 239 P.

BAYER, Hiram de Aquino; DANTAS, Eugênia Maria. Notas teóricas. Notas teóricas para o estudo do medo pela Geografia. Cofins. n. 36, p. 1-10, 16 mar. 2018.

BAYER, Hiram. Pelos caminhos de um labirinto: reflexões sobre as territorializações do medo no bairro de Candelária, Natal-RN. 2010. Tese (Mestrado em Geografia) - UFRN, [S. l.], 2016. Disponível em:

http://repositorio.ufrn.br/handle/123456789/2

1306. Acesso em: 11 fev. 2019

Conceito de movimento socioterritorial.

Boletim DATALUTA. [S. l.], Fevereiro 2015. Disponível em:

https://docplayer.com.br/78575859-Osterritorios-a-via-campesina-no-brasil-e-oconceito-de-movimento-socioterritorial.html. Acesso em: 22 mar. 2019.
CLAVAL , Paul. Terra dos Homens. São Paulo: Contexto, 2017. . Epistemologia Da Geografia. Santa Catarina: Editora UFSC, 2014.

XVII Congresso Nacional de Geografia, $18^{\circ} .2016$, SÃO LUIS- MA.

Território, violência e criminalidade: uma análise geográfica sobre os índices de homícidios no bairro do Paar em Ananindeus-PA.... [S.l.: s.n.], 2010.12 p.

FOUCAULT, Michel. Vigiar e Punir: nascimento da prisão. Petrópolis, RJ: Vozes, 2004.

GOMES, Paulo Cesar da Costa. O lugar do olhar. São Paulo: Bertrand Brasil, 2017. Quadro Geográfico. RIO DE JANEIRO: Bertrand Brasil, 2013.

HAESBAERT, Rogério. Dos multiplos territórios a multiterritorialidade. [S.I], setembro 2004. Disponível em: https://www.passeidireto.com/arquivo/176846 32/dos-multiplos-territorios-as multiterritorialidades. Acesso em: 22 mar. 2019.

HAESBAERT, Rogério. $O$ mito da desterritorialização: do fim dos territórios á 
multiterritorialidade. Rio de Janeiro: Bertrand Brasil, 2006.

Las 50 ciudades más violentas del mundo 2018. [S. l.], 2019. Disponível em: https

://seguridadjusticiaypaz.org.mx/files/estudio.pd f. Acesso em: 22 mar. 2019

MELARA, Eliane. A dinâmica da violência criminal no espaço urbano de Santa Maria - RS. [S.l.: s.n.], 2008. 182 p.

MELGAÇO, LUCAS. Securitização Urbana: da psicoesfera do medo e á tecnosfera da segurança. 2009. 274 p. Dissertação (Doutorado em Geografia)- USP, [S.l.], 2010.

Metodología del ranking (2018) de las 50 ciudades más violentas del mundo [S. l.], 2019. Disponível em:

https/seguridadjusticiaypaz.org.mx/files/Metod ologia.pdf. Acesso em: 22 mar. 2019

MINAYO, Maria Cecília. Conceitos, teorias e tipologias de violência: a violência faz mal à saúde. [S. l.], 2007. Disponível em: http://www1.londrina.pr.gov.br/dados/images/ stories/Storage/sec_mulher/capacitacao_rede\% 20/modulo_2/205631conceitos_teorias_tipologias_violencia.pdf. Acesso em: 22 mar. 2019.
MORAIS, Regis. O que é violência Urbana. São Paulo: Editora Brasiliense, 1995.

NIEVES RIBEIRO, Leandro.Os territórios, a via campesina no Brasil e o conceiro de movimento socioterritorial. Boletim DATALUTA , [S.l.], Fevereiro 2015. Disponível em:https://docplayer.com.br/78575859-Osterritorios-a-via-campesina-no-brasil-e-oconceito-de-movimento-socioterritorial.html. Acesso em: 22 mar. 2019.

RAFFESTIN, Claude. Por uma Geografia do poder. São Paulo: Editora Ática S.A., 1993.

SANTOS, Luciana. O Medo Contemporâneo: Abordando suas diferentes concepções. [S.l.], 2003. $10 \mathrm{p}$

SANTOS, Milton. Metamorfose do Espaço Habitado. São Paulo: Edusp, 2014.

TENÒRIO, Inês de Moura; PIMENTEL Melina. CONCEITUANDO VIOLENCIA. Disponível em: http://portalsocial.sedsdh.pe.gov.br/sigas/ead/ old/arquivos/tematica $04 /$ conceituando $\% 20 \mathrm{a} \%$ 20violencia \%20\%oturma \%2008\%20\%texto\%2 01.pdf.Acesso em: 10 mar.2019

TUAN, Yi-Fu. Paisagens do medo. São Paulo: Editora UNESP, 2005. 